(C) Dereito Vol.27, no:127-146 (Xullo-Decembro, 2018) • ISSN 1132-9947

\title{
OS PROCEDIMENTOS DE DETERMINAÇÃo DOS PREÇOS DE TRANSFERÊNCIA
}

The procedures for determining transfer prices

DOI: http://dx.doi.org/10.15304/dereito.27.2.4498

JosÉ DE CAMPOS AMORIM

Professor Coordenador de Direito Fiscal no ISCAP (Porto)

Instituto Superior de Contabilidade e Administraçâo do Porto

j.camposamorim@gmail.com

\section{Resumo}

Os preços de transferência baseiam-se no princípio da plena concorrência que assenta no pressuposto de que as transações que ocorrem entre empresas relacionadas devem ser idênticas às transações ocorridas entre empresas independentes. Para calcular os preços de transferência podem ser utilizados métodos tradicionais ou métodos não tradicionais. $O$ não cumprimento do princípio da plena concorrência pode levar a correções fiscais efetuadas pela Autoridade Tributária agravando assim o montante de imposto a entregar ao Estado.

Palavras-chave: Preços de transferência, Princípio de plena concorrência, Métodos tradicionais, Métodos não tradicionais, Sociedades.

\section{Abstract}

The transfer pricing is based in the arm 's length principle, which is based on the assumption that transactions taking place between related companies must be identical to transactions occurred between the independent companies. Traditional or non-traditional methods can be used to calculate the transfer pricing. Failure to comply with arm 's length principle, may lead to tax corrections made by the tax administration that will increase the amount of tax due to the state.

Keywords: Transfer pricing, Arm's length principle, Traditional methods, Non-traditional methods, Companies.

\section{Resumen}

Los precios de transferencia se basan en el principio de plena competencia que parte del supuesto de que las transacciones que se produzcan entre empresas relacionadas deben ser idénticas a las transacciones entre empresas independientes. Para calcular los precios de transferencia pueden utilizarse métodos tradicionales o métodos no tradicionales. El incumplimiento del principio de plena competencia puede llevar a correcciones fiscales efectuadas por la Autoridad Tributaria agravando así el importe de impuesto que debe entregarse al Estado.

Palabras clave: Métodos tradicionales, Métodos no tradicionales, Precios de transferencia, Principio de la plena competencia. 


\section{SUMÁRIO}

1.INTRODUÇÃO.; -2. EVOLUÇÃO DAS DISPOSIÇÕES LEGAIS NO CONEXTO INTERNACIONAL E NACIONAL.; -3. PRINCÍPIO DA PLENA CONCORRÊNCIA E ELEMENTOS DE COMPARABILIDADE.; -4.NATUREZA DAS OPERAÇÕES VINCULADAS.; -5.OS MÉTODOS DE DETERMINAÇÃO DOS PT.; -5.1. TIPOLOGIA E SUBSIDIARIEDADE.; COMPARÁVEL DE MERCADO (MPCM).; -5.3.0 MÉTODO DO PREÇO DE REVENDA MINORADO (MPRM).; -5.4.0 MÉTODO DO CUSTO MAJORADO (MCM).; -5.5. DA TRANSIÇÃO DOS MÉTODOS TRADICIONAIS PARA OS MÉTODOS NÃO TRADICIONAIS.; -5.6.0 MÉTODO DO FRACIONAMENTO DO LUCRO (MFL).- 5.7. O MÉTODO DA MARGEM LÍQUIDA DA OPERAÇÃO (MMLO).- 5.8. REGIME EXCECIONAL.; -5.8.1ACORDOS DE PARTILHA DE CUSTOS.; -5.8.2. ACORDOS DE PRESTAÇÃO DE SERVIÇOS INTRAGRUPO.; -6.ANÁLISE SECTORIAL E FUNCIONAL.; -6.1.ANÁLISE SECTORIAL.; -6.2.ANÁLISE FUNCIONAL.; -6.3.PROCEDIMENTO A ADOTAR.; - 7.CONCLUSÃO.; - 8.BIBLIOGRAFIA.

\section{SUMARIO}

1. INTRODUCCIÓN.; -2.EVOLUCIÓN DE LAS DISPOSICIONES LEGALES EN EL CONEXTO INTERNACIONAL Y NACIONAL.; -3.PRINCIPIO DE LA PLENA COMPETENCIA Y ELEMENTOS DE COMPARABILIDAD.; -4.NATURALEZA DE LAS OPERACIONES VINCULADAS.; -5.LOS MÉTODOS DE DETERMINACIÓN DE LOS PT.; -5.1.TIPOLOGÍA Y SUBSIDIARIEDAD.; -5.2.EL MÉTODO DEL PRECIO DE MERCADO COMPARABLE (MPCM).; -5.3.EL MÉTODO DEL PRECIO DE REVENTA MINORADO (MPRM).; -5.4.EL MÉTODO DEL COSTE MAYOR (MCM).; -5.5.DE LA TRANSICIÓN DE LOS MÉTODOS TRADICIONALES A LOS MÉTODOS NO TRADICIONALES.; -5.6.EL MÉTODO DEL FRACCIONAMIENTO DEL BENEFICIO (MFL).; -5.7.EL MÉTODO DEL MARGEN NETO DE LA OPERACIÓN (MMLO).; -5.8.RÉGIMEN EXCEPCIONAL.; -5.8.1ACUERDOS DE REPARTO DE COSTES.; -5.8.2. ACUERDOS DE PRESTACIÓN DE SERVICIOS INTRAGRUPO; -6.ANÁLISIS SECTORIAL Y FUNCIONAL.; -6.1.ANÁLISIS SECTORIAL.; -6.2.ANÁLISIS FUNCIONAL.; -6.3.PROCEDIMIENTO A ADOPTAR.; -7.CONCLUSIÓN.; -8. BIBLIOGRAFÍA.

\section{SUMMARY}

1.INTRODUCTION.; -2.EVOLUTION OF LEGAL PROVISIONS IN THE INTERNATIONAL AND NATIONAL CONNECTION.; -3.PRINCIPLE OF FULL COMPETITION AND ELEMENTS OF COMPARABILITY.; -4.NATURE OF RELATED OPERATIONS.; -5.METHODS OF DETERMINATION OF PT.; -5.1. TYPOLOGY AND SUBSIDIARITY.; -5.2.THE COMPARABLE MARKET PRICE METHOD (MPCM).; -5.3.THE METHOD OF RESALE PRICE REDUCTION (MPRM).; -5.4.THE COST PLUS METHOD (MCM).; -5.5.THE TRANSITION FROM TRADITIONAL METHODS TO NON-TRADITIONAL METHODS.- 5.6. THE METHOD OF FRACTIONING PROFIT (MFL).; -5.7.THE NET MARGIN METHOD OF THE OPERATION (MMLO).; -5.8. EXCEPTIONAL REGIMEN.; 5.8.1EXPENSIVE ARRANGEMENTS.; -5.8.1.INTRA-GROUP SERVICE PROVISION AGREEMENTS.; -6.SECTORAL AND FUNCTIONAL ANALYSIS.; - 


\subsection{SECTORAL ANALYSIS.; -6.2.FUNCTIONAL ANALYSIS.; $\quad$-6.3. PROCEDURE TO ADOPT.; -7.CONCLUSION.; -8.BIBLIOGRAPHY.}

\section{INTRODUÇÃO}

O regime português de preços de transferência tem por base os Princípios Orientadores em Matéria de Preços de Transferência destinados às Empresas Multinacionais da OCDE e encontra-se regulado no artigo 63.0 do Código do Imposto sobre o Rendimento das Pessoas Coletivas (CIRC) e na Portaria n.0 1446 - C/2001, de 21 de dezembro.

Este regime visa assegurar que as receitas fiscais não sejam diminuídas em consequência da transferência de resultados entre empresas do mesmo grupo. Para evitar uma possível "manipulação" dos preços de transferência, o artigo $63^{\circ}$ do Código do IRC e a Portaria n. ${ }^{\circ}$ 1446 - C/2001 estabelecem que, nas operações comerciais, incluindo, designadamente, operações ou séries de operações de bens, direitos ou serviços, bem como financeiras, efetuadas entre um sujeito passivo e qualquer outra entidade, sujeita ou não a IRC, com a qual esteja em situação de relações especiais, devem ser contratados, aceites e praticados termos ou condições substancialmente idênticos aos que normalmente seriam contratados, aceites e praticados entre entidades independentes em operações comparáveis, i.e., essas operações ou séries de operações devem cumprir o princípio de plena concorrência entre empresas relacionadas.

Pretende-se, através deste regime, que as transações que ocorrem entre empresas do mesmo grupo, não tenham como objetivo principal a deslocalização dos lucros de empresas para outras com vista à otimização fiscal ou à realização de um planeamento fiscal abusivo, isto é, à obtenção de vantagens fiscais que não seriam alcançadas, total ou parcialmente, sem utilização desses meios.

Devido a esta problemática surge assim a necessidade de implementar regras em matéria de preços de transferência (PT), baseadas no princípio da plena concorrência, em que as transações que ocorrem entre empresas relacionadas devem ser idênticas às transações ocorridas entre empresas independentes, no sentido de comprovar que não existem motivos externos à simples transação realizada que tenham como finalidade a otimização fiscal ou a deslocalização de lucros.

Com base neste pressuposto, este artigo pretende demonstrar duma forma bastante clara e sucinta alguns aspetos relacionados com o regime de PT e não explorar todas as temáticas, o que seria impossível de alcançar em apenas um artigo tendo em conta a magnitude deste tema. Dessa forma este artigo apresenta um enquadramento teórico que visa analisar o regime dos PT e os métodos consagrados para a aplicação do regime. Por fim, serão apresentadas as principais conclusões.

\section{EVOLUÇÃO DAS DISPOSIÇÕES LEGAIS NO CONEXTO INTERNACIONAL E NACIONAL}

Com a crescente internacionalização da economia, os Estados foram obrigados, a partir dos anos 70, a rever os seus sistemas fiscais no 
sentido de combater manipulações dos PT e de reforçar os seus mecanismos de controlo sobre os PT praticados entre entidades relacionadas.

Este regime enfrenta bastantes obstáculos devido à complexidade das transações comerciais, à dificuldade em aplicar os métodos de determinação dos PT, à reticência dos Estados em promover uma cooperação administrativa em matéria fiscal e à falta de consenso em estabelecer regras de comparabilidade entre operações substancialmente idênticas. Todos estes obstáculos não têm facilitado o exercício da comparabilidade entre as operações substancialmente idênticas nas relações especiais estabelecidas entre entidades relacionadas.

Esta temática, tem levado os Estados a adotarem medidas a nível interno e internacional no sentido de limitar todo o tipo de prática abusiva por parte dos grupos económicos que retiram dos PT um conjunto de vantagens fiscais para $o$ seu desenvolvimento económico comparativamente com os regimes de tributação menos incentivadores noutros países.

Ao nível internacional, foram aprovados pela OCDE em 1979 os Princípios diretores aplicáveis aos PT e dirigidos às empresas multinacionais e às administrações fiscais - The Transfer Pricing Guidelines for Multinational Enterprises in Tax Administrations (terminologia inglesa) - (doravante designados Princípios Diretores da OCDE) ${ }^{1}$, prevendo que os PT sejam determinados de acordo com os princípios da substância económica e da plena concorrência. Ao nível da União Europeia (EU), foram determinadas várias medidas ${ }^{2}$, entre as quais se destaca o Código de Conduta sobre a Fiscalidade das Empresas, aprovado em I de dezembro de 1997 pelo Conselho da União Europeia (CUE) e pelos Ministros das Finanças dos Estados-membros ${ }^{3}$, prevendo, entre outros, a cooperação entre os Estados-membros em relação às medidas suscetíveis de terem uma influência na localização das atividades económicas na UE. Salienta-se igualmente a comunicação da Comissão Europeia (CE) sobre PT no domínio da prevenção e resolução de litígios e as diretrizes sobre os acordos prévios em matéria de PT na UE ${ }^{4}$.

No contexto nacional, o legislador português consagrou no art. $63 .{ }^{\circ}$ do CIRC uma norma anti-abuso destinada a corrigir a matéria coletável no caso dos termos ou condições das operações sobre bens, serviços e

\footnotetext{
${ }^{1}$ Estes Princípios Diretores da OCDE constituem uma revisão do relatório da OCDE sobre os PT e as empresas multinacionais de 1979. Foram inicialmente aprovados pelo Comité dos assuntos fiscais em 27 de junho de 1995 e pelo Conselho da OCDE em 13 de julho de 1995 para publicação. Ver Silberztein, Caroline, "The 2010 uptade to the OECD. Transfer Pricing Guidelines", in Dennis Weber and Stef van Weeghel, The 2010 OECD Updates. Model Tax Convention \& Transfer Pricing Guidelines. A Critical Review, Kluwer Law International BV, Holanda, 2011, p. 147-160.

${ }^{2}$ A. C. DOS SANTOS e C. CELORICO PALMA, «A regulação internacional da concorrência fiscal prejudicial», CTF, no 395, julho-setembro 1999, p. 9-36.

${ }^{3}$ Resolução do Conselho e dos Representantes dos governos dos Estados-membros de 1 de dezembro de 1997 relativa a um código de conduta no domínio da fiscalidade das empresas (98/C 2/01).

${ }^{4}$ SEC (2007) 246) / COM/2007/0071 final.
} 
direitos não serem substancialmente idênticos aos que normalmente seriam contratados, aceites e praticados entre entidades independentes em operações comparáveis. Esta norma anti-abuso define claramente o princípio de plena concorrência que deve estar subjacente em todas as transações. Este artigo define ainda o que são relações especiais, adverte para a necessidade de reunir a documentação respeitante à política dos PT, define os métodos que asseguram a comparabilidade das operações e, por fim, alerta para a necessidade do preenchimento da Informação Empresarial Simplificada (IES) relativamente às matérias de PT.

Adicionalmente, foi transposto também para o ordenamento jurídico português uma das ações definidas no Base Erosion and Profit Shifting (BEPS) $)^{5}$, aprovado em 2013, através do art. 121.0 - A do CIRC, que define os grupos de empresas que se devem submeter ao Country-by-Country Reporting (CbCR).

$\mathrm{Na}$ legislação nacional, destaca-se ainda a Portaria 1446-C/2001, de 21 de dezembro, que refere os métodos de determinação dos preços (extraídos da OCDE), a aplicação do princípio da plena concorrência, a fixação das margens brutas, das margens líquidas e de outros indicadores de referência indispensáveis para aferir a comparabilidade entre as operações vinculadas e as operações entre entidades independentes. São igualmente apresentados os tipos de acordos mais comuns celebrados entre entidades relacionadas, passando pela apresentação da informação que deve ser apresentada no dossier de PT. Esta portaria termina com a apresentação do ajustamento correlativo que não é mais do que a decisão da AT em efetuar ajustamento à matéria coletável por virtude de relações especiais.

Também integra o contexto nacional a Portaria n. ${ }^{\circ}$ 620-A/2008, de 16 de julho, que visa regulamentar a possibilidade de celebração de acordos prévios sobre PT e fixar previamente os métodos a utilizar na determinação dos preços entre entidades relacionadas ${ }^{6}$. Estes acordos são designados de Advanced Pricing Agreements (APA'S) que consistem num acordo celebrado entre uma ou mais AT e um contribuinte (regra geral uma multinacional) que permite definir previamente à realização de operações vinculadas, um conjunto de critérios adequados com vista à determinação dos PT aplicáveis a essas operações durante um determinado período de tempo. Estes acordos têm como principal objetivo evitar que uma política adotada por uma empresa possa ser questionada pela AT no futuro.

\footnotetext{
${ }^{5}$ A OCDE apresentou, com o apoio político do G20, o BEPS, que visa o combate à erosão da base tributária e ao desvio de lucros para jurisdições de baixa tributação. Este plano pretende marcar o fim de uma época de laissez-faire e assinala uma nova era de intervenção dos Estados traduzindo-se, concretamente, na elevação do padrão das melhores práticas a serem implementadas, no plano fiscal, pelas empresas no âmbito das suas atividades, bem como do nível de equidade em matéria de pagamento de impostos.

${ }^{6}$ A. C. AZEVEDO DE AMORIM, "Acordos prévios em matéria de PT", em D. LEITE DE CAMPOS, Estudos de Direito Fiscal, Almedina, 2007, p. 29-52.
} 
Em 23 de maio de 2016, o Conselho da OCDE aprovou novas alterações às Diretrizes dos Preços de Transferência para Empresas Multinacionais e Administrações Tributárias ("Diretrizes de Preços de Transferência"), prevendo que as Diretrizes dos Preços de Transferência sejam integradas na legislação nacional, inclusive fazendo uma referência direta às próprias Diretrizes.

A edição de 2017 das Diretrizes da OCDE incorpora mudanças substanciais em relação a 2016 no sentido de refletir as mudanças e esclarecimentos acordados nos relatórios de 2015 sobre as Ações 8 a 10 da BEPS, as quais visam garantir que os resultados dos preços de transferência estão de acordo com a Ação 13 (Documentação sobre preços de transferência e Relatório por país). Esta nova edição determina igualmente que um regime de proteção pode aliviar determinados encargos de cumprimento das obrigações fiscais e proporcionar uma maior segurança aos contribuintes ${ }^{7}$.

\section{PRINCÍPIO DA PLENA CONCORRÊNCIA E ELEMENTOS DE COMPARABILIDADE}

O princípio da plena concorrência, designado por "arm's length principle" estabelece que nas operações comerciais estabelecidas entre entidades relacionadas devem ser contratados, aceites e praticados termos ou condições substancialmente idênticos aos que normalmente seriam contratados, aceites e praticados entre entidades independentes em operações comparáveis, de acordo com 0 nº 1 do art. $63 .{ }^{\circ}$ do Código do IRC. Este princípio determinante dos PT visa tratar os membros de um grupo multinacional como entidades não relacionadas e dissociáveis do grupo a que pertencem.

Os elementos de comparabilidade a ter em conta têm que ver, entre outros, com as características dos produtos ou serviços transmitidos, as funções que as entidades desempenham (produção, venda, investigação, marketing, administração, gestão, etc.), as condições e os temos contratuais, as circunstâncias económicas e as estratégias industriais e comerciais que as entidades prosseguem. Com base nestes elementos, procede-se à comparação entre as operações ou transações desenvolvidas pelas entidades relacionadas e as operações ou transações comparáveis no mercado aberto.

Para efetuar a comparabilidade é necessário fazer uma análise económica e medir a comparabilidade entre as operações praticadas entre empresas relacionadas. A análise económica visa aferir a conformidade das transações intra-grupo com o princípio de plena concorrência, com base num dos métodos de determinação dos preços de transferência específicos.

\footnotetext{
7 OECD (2018), Directrices de la OCDE aplicables en materia de precios de transferencia a empresas multinacionales y administraciones tributarias, OECD Publishing, Paris/Instituto de Estudios Fiscales, Madrid, https://doi.org/10.1787/9788480083980-es.
} 
Para avaliar a conformidade das transações ao princípio de plena concorrência, devem ser considerados o grau de comparabilidade entre os termos e condições praticados numa operação vinculada e os termos e condições praticados numa operação entre empresas independentes, a qualidade da informação disponível e os eventuais ajustamentos necessários para eliminar as diferenças existentes entre as operações entre empresas independentes e as entidades relacionadas. De acordo com o n.0 3 do artigo $4 .^{\circ}$ da Portaria, para que duas operações possam ser consideradas "suficientemente similares" é necessário que "(...) as diferenças existentes entre as operações ou entre as empresas nelas intervenientes não sejam suscetíveis de afetar de forma significativa os termos e condições que se praticariam numa situação normal de mercado".

O grau de comparabilidade é avaliado, segundo o art. 0 5. ${ }^{\circ}$ da Portaria n. ${ }^{\circ} 1446-C / 2001$, de acordo com as características dos bens, direitos ou serviços que são suscetíveis de influenciar o preço das operações e, em particular, as características físicas, a qualidade, a quantidade, a fiabilidade, a disponibilidade e o volume de oferta dos bens, a forma negocial, o tipo, a duração, o grau de proteção e os benefícios antecipados pela utilização do direito e a natureza e a extensão dos serviços (al. a); as funções desempenhadas pelas entidades intervenientes nas operações, tendo em consideração os ativos utilizados e os riscos assumidos (al. b); os termos e condições contratuais que definem, de forma explícita ou implícita, o modo como se repartem as responsabilidades, os riscos e os lucros entre as partes envolvidas na operação (al. c); as circunstâncias económicas prevalecentes nos mercados em que as respetivas partes operam, incluindo a sua localização geográfica e dimensão, a posição concorrencial dos compradores e vendedores, a fase do circuito de comercialização, a existência de bens e serviços sucedâneos, o nível da oferta e da procura e o grau de desenvolvimento geral dos mercados (al. d); e a estratégia das empresas, contemplando, entre os aspetos suscetíveis de influenciar o seu funcionamento e conduta normal, a prossecução de atividades de pesquisa e desenvolvimento de novos produtos e/ou serviços, o grau de diversificação da atividade, o controle de risco, os esquemas de penetração no mercado ou de manutenção ou reforço de quota e, bem assim, os ciclos de vida dos produtos ou direitos (al. e).

Contudo, a Portaria n.o 1446-C/2001, no seu art. 4.0, n.o 3, prevê que, se as diferenças existentes entre operações vinculadas e não vinculadas não afetarem de forma significativa os termos e condições praticados, essas operações poderão ser comparáveis desde que seja "(...) possível efetuar os necessários ajustamentos que eliminem os efeitos relevantes provocados pelas diferenças verificadas".

Neste contexto, o sujeito passivo deve dispor de informação e documentação respeitantes à política adotada na determinação dos preços de transferência e manter elementos aptos a provar a respetiva paridade com o mercado. Os sujeitos passivos cujos proveitos tenham atingido, no 
exercício anterior, um montante superior a 3.000.000 de euros, devem dispor de informação e documentação respeitantes às políticas adotadas na determinação dos preços de transferência, incluindo a fundamentação do(s) método(s) de análise dos preços de transferência selecionado(s) e as análises ao cumprimento do princípio de plena concorrência nas operações estabelecidas com entidades relacionadas.

\section{NATUREZA DAS OPERAÇÕES VINCULADAS}

De acordo com a alínea a) do $\mathrm{N}^{0} 1$ da portaria $1446-\mathrm{C} / 2001$, de 21 de dezembro, o termo operações abrange as operações financeiras e comerciais, incluindo qualquer operação ou série de operações que tenha por objeto bens tangíveis e intangíveis, direitos ou serviços, ainda que realizadas no âmbito de um qualquer acordo de partilha de custos e de prestação de serviços intra-grupo, ou de uma alteração de estruturas de negócio, em especial quando esta envolva a transferência de elementos intangíveis ou a compensação de danos emergentes ou lucros cessantes. Quanto à natureza das operações vinculadas, a alínea b) do $n^{\circ} 1$ desta mesma portaria remete para o art. $63 .{ }^{\circ}$ do CIRC que consagra no n. ${ }^{\circ} 4$ os tipos de relações vinculadas, as quais serão a seguir devidamente explicadas.

Tal como já foi referido, o regime de preços de transferência é aplicável a operações ou séries de operações vinculadas entre as entidades residentes, entre um estabelecimento estável português de uma sociedade estrangeira e essa mesma sociedade ou um outro estabelecimento estável noutro país, e entre uma entidade residente, incluindo um estabelecimento estável português, e qualquer outra entidade não residente.

Além disso, as regras de preços de transferência estabelecem que duas entidades estão em situação de relação especial sempre que uma delas tenha o poder de exercer, direta ou indiretamente, uma influência significativa nas decisões de gestão da outra, tal como sucede no caso de uma entidade deter, direta ou indiretamente, pelo menos $20 \%$ do capital ou dos direitos de voto de outra entidade; ou quando os membros dos órgãos sociais das entidades são comuns ou estão ligados por casamento ou parentesco próximo; ou ainda quando as atividades económicas desenvolvidas por uma entidade estão em larga medida dependentes de outras entidades, através de dependência comercial, financeira ou jurídica. Nas várias alíneas do n04 do art. $63 .{ }^{\circ}$ do CIRC são enumeradas as várias situações em que se considera estarmos na presença de relações especiais. Podemos assim dividir as alíneas em duas grandes categorias, nomeadamente que existe uma entidade relacionada sob o ponto de vista societário (em função da relação de participação) ou no plano da dependência económica.

Sob o ponto de vista do plano societário podemos afirmar que uma entidade apresenta relações especiais com outra quando: (i) A empresa $A$ detêm $47 \%$ da Empresa B, (ii) Os acionistas $X$ e $Y$ detêm $40 \%$ do capital da Empresa $A$ e da Empresa $B$, (iii) $O$ CEO da empresa $A$ é cônjuge do 
CEO da empresa B e (iv) A empresa A vende $90 \%$ de toda a sua produção à Empresa $\mathrm{B}$.

Sob o ponto de vista da dependência económica, as entidades relacionadas são aquelas que estão ligadas por um contrato de subordinação, de grupo paritário ou outro de efeito equivalente (al. e) do n. 04 ); as empresas que se encontrem em relação de domínio, nos termos do artigo $486 .{ }^{\circ}$ do Código das Sociedades Comerciais (al. f) do n.o 4); as entidades cujo relacionamento jurídico possibilita, pelos seus termos e condições, que uma condicione as decisões de gestão da outra, em função de factos ou circunstâncias alheios à própria relação comercial ou profissional (al. g) do n.0 4); e uma entidade que estabeleça operações comerciais com outra entidade sujeita a um regime fiscal claramente mais favorável (al. h) do n.o 4).

Uma vez analisado o princípio da plena concorrência e identificadas as entidades relacionadas e o tipo de operações vinculadas, podemos agora passar para um dos pontos fundamentais deste processo que assenta na definição do método a utilizar.

\section{OS MÉTODOS DE DETERMINAÇÃO DOS PT}

\subsection{Tipologia e subsidiariedade}

De acordo com os Princípios Diretores da OCDE, os métodos de determinação dos $\mathrm{PT}^{8}$ podem ser classificados em métodos tradicionais, baseados em transações, e métodos não tradicionais, baseados no lucro apurado. Estes métodos são utilizados para determinar se as condições que regem as relações comerciais ou financeiras entre empresas relacionadas estão de acordo com o princípio de plena concorrência ${ }^{9}$.

Integram a primeira categoria o método do preço comparável de mercado (MPCM), o método do custo majorado (MCM) e o método do preço de revenda minorado (MPRM), os quais são aplicados apenas nos casos em que é possível comparar os termos e condições das transações ou operações efetuadas entre entidades relacionadas com os que vigorariam se as transações ou operações fossem realizadas entre entidades independentes.

$\mathrm{Na}$ segunda categoria, incluem-se o método do fracionamento do lucro (MFL) e o método da margem líquida da operação (MMLO), ambos baseados no lucro das atividades das entidades relacionadas comparativamente com o lucro de entidades independentes.

$\mathrm{O}$ que distingue fundamentalmente os primeiros dos segundos reside no facto de os métodos tradicionais basearem-se nas operações

\footnotetext{
${ }^{8}$ G. MAISTO, "OECD Revision of Chapters I-III and IX of the Transfer Pricing Guidelines: Some Comments on Hierarchy of Methods and Re-characterization of Actual Transactions Undertaken", in The 2010 OECD Updates. Model Tax Convention \& Transfer Pricing Guidelines. A Critical Review, Edited by D. WEBBER and S. VAN WEEGHEL, Kluwer Law International BV, The Netherlands, 2011, p. 173-182; B. J. ARNOLD and M. J. MCINTYRE, "International Tax Primer", $2^{\circ}$ ed., Kluwer Law International, The Hague, 2002, p. 55-80. ${ }^{9}$ Faria, Maria Teresa Veiga de, "Sobre os métodos de determinação de PT", in Ciência e Técnica Fiscal, Centro de Estudos Fiscais, n. 0 400, dezembro 2000, p. 61-159.
} 
efetivamente realizadas enquanto que os não tradicionais têm por base o lucro das operações.

O objetivo dos métodos tradicionais é comparar o preço praticado entre empresas relacionadas e empresas independentes, tendo em conta as condições em que as operações foram realizadas, o que nem sempre é possível devido à multiplicidade de elementos de comparabilidade, à indisponibilidade da informação e à dificuldade em averiguar a fiabilidade da informação disponível. Os métodos tradicionais são aqueles métodos que melhor determinam se as relações comerciais e financeiras entre empresas relacionadas preenchem ou não as regras da plena concorrência.

Quanto aos métodos não tradicionais, estes têm por base os lucros obtidos por entidades relacionadas no âmbito de operações especiais. As empresas podem aplicar o MFL ou o MMLO para fixarem os seus preços de plena concorrência. São métodos que visam determinar os PT de acordo com os lucros obtidos na sequência de uma operação vinculada e que devem ser compatíveis com o Modelo de Convenção da OCDE.

Os métodos baseados no lucro devem ser aplicados se forem compatíveis com o art. 9. ${ }^{\circ}$ do Modelo de Convenção Fiscal OCDE, isto é, se as condições impostas às entidades relacionadas forem comparáveis às condições estabelecidas entre empresas independentes em termos de preços, margens ou lucros obtidos. Por outras palavras, os preços, margens ou lucros de entidades relacionadas devem ser semelhantes aos preços, margens ou lucros praticados por entidades independentes ${ }^{10}$.

Os métodos não tradicionais aplicam-se quando os métodos tradicionais não são suficientemente fiáveis ou são insuficientes para a sua aplicação. Sendo os métodos não tradicionais subsidiários dos métodos tradicionais, as empresas não estão impedidas de proceder à aplicação direta dos métodos não tradicionais nos casos de especial interesse para os grupos de sociedades.

A seleção do método mais adequado depende de um conjunto de fatores, que têm que ver com a natureza da operação, o tipo de produto e o setor de atividade, não existindo, na verdade, um método que possa ser aplicável em toda e qualquer circunstância, devendo ser sempre adotado o método que, face aos factos e circunstâncias específicas de cada operação, satisfaça de forma mais apropriada o princípio de plena concorrência.

O sujeito passivo deverá selecionar o método mais apropriado para cada operação e que melhor se adequa ao preço de plena concorrência ou a produzir a melhor estimativa de um preço de mercado. Esse método deverá assegurar o mais elevado grau de comparabilidade entre as operações vinculadas e operações entre entidades independentes. Caso não seja possível aplicar nenhum dos métodos tradicionais e não tradicionais, os Princípios Diretores da OCDE admitem a possibilidade de utilização de outros métodos e a opção por uma solução que seja

10 OCDE, Transfer Pricing Guidelines for Multinational Enterprises and Tax Administrations, julho 2017, § 2.6. 
satisfatória para todas as partes e que esteja em harmonia com o princípio da plena concorrência. Trata-se de fazer a opção por um método de acordo com os termos e as condições praticadas nas operações e transações realizadas entre entidades relacionadas e a informação disponível no mercado.

O preço de plena concorrência praticado numa operação vinculada deve ser testado através de métodos baseados nas operações (métodos tradicionais) ou no lucro das operações (métodos não tradicionais). Os primeiros dizem respeito ao método do preço comparável de mercado, ao método do preço de revenda minorado e ao método do custo majorado. Os métodos baseados no lucro das operações respeitam ao método do fracionamento do lucro e ao método da margem líquida da operação.

A Portaria estabelece uma preferência pelos métodos tradicionais, admitindo o recurso aos métodos transacionais de lucros quando os tradicionais não possam ser aplicados ou não permitam obter a medida mais fiável dos termos e condições que entidades independentes aceitariam.

Deste modo, apresenta-se abaixo uma breve descrição dos métodos de preços de transferência previstos na Portaria para a determinação dos preços de plena concorrência.

\subsection{O método do preço comparável de mercado (MPCM) ${ }^{11}$}

O MPCM é o método especialmente indicado para a avaliação do preço de plena concorrência das transações de natureza idêntica, cujos produtos e serviços tenham um elevado grau de equiparabilidade ${ }^{12}$. O MPCM compara o preço praticado em operações vinculadas com o preço praticado em operações em mercado aberto.

As operações comparáveis podem ser as efetuadas entre entidades independentes ou entre uma das entidades relacionadas e uma entidade independente. O MPCM é a medida de avaliação do preço de plena concorrência mais ajustada para as operações idênticas ou semelhantes.

O MPCM requer um elevado grau de comparabilidade entre as operações ou transações efetuadas, nomeadamente ao nível das condições e termos do contrato, dos serviços prestados e/ou dos produtos transmitidos, das condições económicas, da quantidade de bens adquiridos, das funções desempenhadas e dos riscos cambiais.

Este método deve ser utilizado nas situações em que, por exemplo, uma empresa pertencente a um grupo de sociedades realiza uma transação da mesma natureza que a praticada por uma entidade independente no mesmo mercado ou em mercados similares (comparável interno) e sempre que seja possível encontrar no mercado operações

${ }^{11}$ Descrito no art. ${ }^{\circ} 6 .^{\circ}$ da Portaria n. ${ }^{\circ}$ 1446-C/2001 e no n.० 3, al. a) do art. $63 .{ }^{\circ}$ do CIRC.

${ }_{12}$ S. G. SHERWOOD, Comparable uncontrolled price method, in Robert Feinschreiber (eds), Transfer Pricing Handbook, vol. 1, 3a edição, J. WILEY \& Sons, Inc, United States, 2001, p. $15-1$ e ss. 
praticadas entre entidades independentes da mesma natureza que as operações realizadas entre entidades vinculadas (comparável externo).

Desde que se possa identificar operações comparáveis em mercado aberto, o referido método constitui o meio mais direto e mais fiável de aplicação do princípio de plena concorrência. Por consequência, nestas condições, deve ser dada preferência a este método sobre todos os demais. Caso este método não seja o mais apropriado, é possível recorrer, complementar ou subsidiariamente, a um outro método e proceder assim ao ajustamento necessário do preço para que as operações ocorridas entre entidades relacionadas sejam comparáveis com as mesmas operações ocorridas entre entidades independentes.

Todo o ajustamento que seja necessário efetuar destina-se a restabelecer a equiparabilidade entre o preço praticado entre operações vinculadas e não vinculadas.

\subsection{0 método do preço de revenda minorado (MPRM) ${ }^{13}$}

O método do preço de revenda minorado tem por base o preço de um produto adquirido a uma entidade relacionada e revendido a uma entidade independente. Este método tem por base o preço pelo qual um produto adquirido a uma empresa relacionada é revendido a uma empresa independente. Obtém-se o preço de plena concorrência deduzindo do preço de revenda uma margem de lucro bruto de mercado. O preço de revenda é assim apurado através da dedução de uma margem de revenda apropriada. Esta margem de lucro bruto de mercado é a praticada por empresas independentes, que serve de base à determinação do preço comparável da entidade relacionada, sendo aqui a margem objeto de comparação entre entidades independentes e entidades relacionadas.

Este método, geralmente aplicado a operações de comercialização (distribuição) e marketing, não se limita apenas a comparar as margens de lucro entre produtos adquiridos e revendidos, mas integra também outros fatores como as funções exercidas, o custo das operações, os riscos assumidos, os termos contratuais das operações vinculadas e as circunstâncias económicas que podem alterar o valor dos produtos transferidos e incidir sobre a rentabilidade de uma empresa. Este método é mais indicado para distribuidores que revendem o produto sem o alterar fisicamente e sem Ihe acrescentar valor substancial.

Este método impõe uma análise aos revendedores independentes que desenvolvam operações comparáveis e assumem níveis de risco semelhantes.

\subsection{O método do custo majorado (MCM) $)^{14}$}

O MCM é indicado para avaliar operações e transações desenvolvidas por empresas que produzem bens ou serviços destinados a ser vendidos a entidades com as quais têm relações especiais. O MCM compara a margem de lucro bruto das operações realizadas entre entidades

\footnotetext{
${ }^{13}$ Descrito no art. ${ }^{\circ} 7 .^{\circ}$ da Portaria $1446-\mathrm{C} / 2001$ e no n. ${ }^{\circ} 3$, al. a) do art. ${ }^{\circ} 63 .{ }^{\circ}$ do CIRC.

${ }^{14}$ Descrito no art. $8 .{ }^{\circ}$ da Portaria $1446-\mathrm{C} / 2001$ e no n. ${ }^{\circ} 3$, al. a) do art. $63 .{ }^{\circ}$ do CIRC.
} 
relacionadas e entidades independentes, tendo em conta os custos suportados pelo fornecedor ou prestador de serviços, acrescidos da margem necessária à obtenção do lucro apropriado.

O preço de plena concorrência obtém-se a partir do custo suportado por um fornecedor de bens ou serviços numa operação vinculada e tem em conta as funções exercidas, os riscos suportados e os ativos utilizados. A este custo acresce a margem de lucro bruto ${ }^{15}$ obtida numa transação independente que pode ter sido efetuada por uma entidade pertencente ao mesmo grupo (comparável interno) ou por qualquer entidade independente (comparável externo).

O preço de plena concorrência obtém-se a partir do custo suportado por um fornecedor de bens e serviços no âmbito de uma operação vinculada, ao qual acresce a margem de lucro sobre o preço de custo aplicada por uma empresa do grupo, de modo a obter o lucro bruto da transação ${ }^{16}$.

Este método é especialmente recomendado pela OCDE no caso de venda de produtos semi-acabados entre empresas relacionadas ${ }^{17}$. Este método requer uma comparação detalhada dos bens produzidos, das funções exercidas, dos riscos assumidos, do processo produtivo, da estrutura de custos e dos intangíveis envolvidos entre operações vinculadas e não vinculadas.

\subsection{Da transição dos métodos tradicionais para os métodos não tradicionais}

Os métodos tradicionais permitem determinar de forma direta se as relações económicas ou financeiras entre as entidades relacionadas são efetivamente relações de plena concorrência. A aplicação dos métodos baseados nas operações - métodos não tradicionais - só é possível se as entidades dispuserem de informações suficientes para os aplicar.

Os métodos tradicionais garantem uma maior fiabilidade na determinação dos preços de mercado, desde que exista a garantia da equiparabilidade das operações ou das transações. Caso a informação não esteja disponível ou não seja suficiente para garantir a aplicabilidade destes métodos, deve-se recorrer aos métodos não tradicionais, baseados no lucro da operação. Sempre que os métodos tradicionais não são suficientemente fiáveis, as entidades têm a possibilidade de aplicar métodos baseados no lucro das operações, nomeadamente o método do fracionamento do lucro ou o método da margem líquida da operação. Um destes métodos pode ser utilizado desde que a sua aplicação tenha sido aceite pelas entidades relacionadas e pelas administrações fiscais dos respetivos países.

\footnotetext{
${ }^{15}$ A margem de lucro resulta da diferença entre o preço de venda e o custo de produção.

${ }^{16}$ A margem de lucro resulta da diferença entre o preço de venda e o custo de produção.

${ }^{17}$ Parágrafo 2.32 do Relatório da OCDE de 1995.
} 


\subsection{O método do fracionamento do lucro (MFL) $)^{18}$}

Este método, baseado no lucro das operações, é utilizado para "repartir o lucro global derivado de operações complexas ou de séries de operações vinculadas"19. O lucro global proveniente das operações entre as empresas relacionadas é repartido entre entidades relacionadas de acordo com a contribuição de cada uma na realização das operações, tendo em conta uma série de fatores, tais como as funções exercidas, o capital investido, os ativos utilizados, o poder negocial e os riscos assumidos por cada uma ${ }^{20}$. O lucro global obtido pelas entidades intervenientes é assim repartido entre as diferentes entidades em função da contribuição de cada entidade na realização das operações.

Este método foi concebido para as operações que envolvem um elevado grau de integração, em que não seja possível a avaliação das operações de forma individualizada. Tal sucede quando as partes envolvidas contribuem de forma conjunta para a criação de valores e, portanto, cada uma delas contribuiu para o lucro global.

\subsection{O método da margem líquida da operação (MMLO) ${ }^{21}$}

O MMLO consiste em determinar a margem de lucro líquida numa operação vinculada e compará-la com a margem de lucro líquida de uma operação não vinculada que tenha sido realizada pelo próprio sujeito passivo, por uma entidade do grupo ou por uma entidade independente em circunstâncias comparáveis. Trata-se de um método baseado no lucro líquido das operações que tem em vista comparar os resultados financeiros obtidos numa operação vinculada com a margem líquida obtida em mercado aberto.

A margem de lucro é determinada, tal como no MCM e no MPRM, em função das características de cada operação, isto é, o tipo de atividade, as aquisições efetuadas, as vendas realizadas, os ativos utilizados e os custos incorridos. O MMLO está mais baseado na rentabilidade das transações, isto é, na comparação dos resultados operacionais da entidade relacionada com os resultados operacionais das entidades independentes. Neste sentido, o MMLO equipara-se aos métodos do custo majorado e do preço de revenda minorado, sendo neste caso aplicado à margem líquida das operações ${ }^{22}$. O MMLO utiliza indicadores de rendibilidade baseados na margem de lucro líquido das operações e não na margem de lucro bruto, o que significa que este método não exige um tão elevado grau de similaridade entre produtos.

Este método tem a vantagem de não estar sujeito diretamente à variabilidade dos preços praticados (tal como sucede com o MPCM). O MMLO é um método adequado para determinar o preço comparável de

\footnotetext{
${ }^{18}$ Descrito no art. 9. ${ }^{\circ}$ da Portaria $1446-C / 2001$ e no n. ${ }^{\circ} 3$, al. b) do art. $63 .{ }^{\circ}$ do CIRC.

${ }^{19}$ Art. 9. ${ }^{\circ}$, n. ${ }^{\circ} 1$ da Portaria $1446-\mathrm{C} / 2001$.

20 Art. 9.0, n. ${ }^{\circ} 2$ da Portaria $1446-\mathrm{C} / 2001$.

${ }^{21}$ Descrito no art. $10 .{ }^{\circ}$ da Portaria $1446-\mathrm{C} / 2001$ e no n. ${ }^{\circ} 3$, al. a) do art. $63 .{ }^{\circ}$ do CIRC.

22 J. CARVALHO ESTEVES e C. DIHTMER, "Da relevância do método da margem líquida da operação em sede de PT", in G. TEIXEIRA (coord.), Preços de Transferência. Casos práticos, Ed. Vida Económica, 2006, p. 233.
} 
mercado quando não se possui informações suficientes sobre os termos e condições fixados nas operações vinculadas. Neste sentido, o MMLO acaba por ser mais fiável do que o MFL e os métodos tradicionais nos casos particulares em que não se dispõe de elementos de comparabilidade nos métodos tradicionais.

\subsection{Regime excecional}

Adicionalmente à definição dos métodos de determinação dos preços de plena concorrência, foi definido um regime excecional aplicável às relações entre entidades relacionadas, em matéria de acordos de partilha de custos e de acordos de prestação de serviços estabelecidos intragrupo.

\subsubsection{Acordos de partilha de custos ${ }^{23}$}

Os acordos de partilha de custos pressupõem a repartição dos custos e dos riscos de produzir, desenvolver ou adquirir bens, direitos ou serviços, entre as entidades relacionadas, de forma proporcional às vantagens ou benefícios que cada uma possa vir a obter em função da sua participação, sem o pagamento de qualquer contraprestação adicional.

A possibilidade de estabelecer um acordo de partilha de custos depende do facto de existir uma equivalência de valores entre as contribuições das várias entidades relacionadas e as contribuições praticadas pelas entidades independentes em situações comparáveis. Caso tal não se verifique, deverá existir uma compensação efetiva de modo a que seja restabelecido o equilíbrio pretendido. De referir ainda que para que uma sociedade seja considerada participante neste tipo de acordos, deverá existir, da sua parte, a expectativa de tirar proveito da atividade objeto do acordo (economia de escala ou melhoria de produtividade). Caso contrário, estaremos perante uma prestação de serviços realizada por uma entidade em benefício de outra relativamente a qual deverão ser aplicados os métodos anteriormente referidos.

\subsubsection{Acordos de prestação de serviços intra-grupo ${ }^{24}$}

Nestes acordos podem incluir-se, entre outros, atividades de natureza financeira, comercial, técnica ou administrativa, ressalvando que os serviços previstos no acordo incluam um valor económico relevante para os respetivos destinatários, que justifique o pagamento de um preço ou um gasto que seriam suportados nos mesmos termos se fossem contratados a entidades independentes.

Na determinação do preço deve ser adotado o método direto, sempre que os custos sejam individualizáveis e não definidos em termos globais. No caso de custos globais, deve ser adotado o método indireto, repartindo os custos globais de serviços prestados pelas várias entidades do grupo com base numa repartição justa e adequada, tendo em conta,

\footnotetext{
${ }^{23}$ Descrito no art. $11 .^{\circ}$ da Portaria $1446-C / 2001$.

24 Descrito no art. $12 .^{\circ}$ da Portaria $1446-C / 2001$.
} 
nomeadamente, as margens de lucro, as vendas, as despesas com pessoal, etc.

$\mathrm{Na}$ falta de elementos de comparabilidade, admite-se, em certas circunstâncias, a aplicação do princípio de plena concorrência ao conjunto de transações, desde que a avaliação individual dessas transações revele alguma dificuldade ou não seja possível a análise separada de cada uma das transações.

\section{ANÁLISE SECTORIAL E FUNCIONAL}

\subsection{Análise sectorial}

Os preços de plena concorrência podem variar consoante a natureza dos bens, direitos ou serviços, mas também dependem dos mercados em que operam as empresas. Para que se possam estabelecer comparações, é necessário que os mercados não apresentem diferenças significativas. Por este motivo, na comparação dos mercados, importa ter em conta a localização geográfica, o nível de concorrência dos compradores e dos vendedores, a disponibilidade de bens e de serviços, o nível de oferta e procura, o poder de compra dos consumidores, os custos de produção, transporte e publicidade e as fases do circuito de comercialização.

Relativamente às empresas, podem ser identificar, segundo o art. $1^{\circ}$ da Portaria n.o 1446-C/2001, de 21/12, todo um conjunto de fatores para efeitos de comparabilidade dos preços de transferência. Existem vários aspetos a considerar na análise da comparabilidade das operações efetuadas entre empresas relacionadas e empresas independentes. Os preços e as margens praticados nas transações devem refletir as estratégias empresariais de uma empresa e do respetivo grupo. As estratégias empresariais contemplam aspetos suscetíveis de influenciar os preços de transferência. Deve ser um dos aspetos a considerar nas análises de comparabilidade das operações efetuadas entre empresas relacionadas e entre empresas independentes. A prioridade é atribuída a fatores como o desenvolvimento de novos produtos, o grau de diversificação, as estratégias de penetração no mercado, os termos e condições praticados nas transações intra-grupo e as estratégias empresariais de penetração no mercado destinadas a aumentar a quota de mercado a um preço inferior ao que é praticado nesse mercado para produtos comparáveis.

\subsection{Análise funcional}

A análise das funções, dos riscos e dos ativos constitui a base da metodologia dos preços de transferência e contribui para a análise das condições e termos acordados nas operações vinculadas. Esta fase permite sistematizar os factos mais relevantes do negócio da empresa e, desta forma, compreender as funções de cada uma das entidades envolvidas nas operações vinculadas.

Nesta análise, são tidos em conta as funções desenvolvidas pelas entidades relacionadas intervenientes na operação vinculada, com vista a definir o intervalo de plena concorrência e, consequentemente, os preços ou margens que devem ser praticados nas transações vinculadas em 
análise; a análise dos riscos que as contrapartes da transação vinculada suportam, sendo expectável que, em situações de concorrência, as empresas que suportam maiores níveis de risco possam beneficiar de maiores margens de rendibilidade. A análise de riscos deve ter em consideração, na perspetiva dos preços de transferência, o nível de risco efetivamente suportado pela entidade em análise e o modo como o risco é repartido pelas entidades envolvidas nas operações vinculadas.

A avaliação dos riscos geralmente associados à atividade das empresas têm em conta o risco económico (a conjuntura macroeconómica tem um impacto na procura dos produtos/serviços e nos resultados das empresas), o risco de mercado (alterações nas preferências dos clientes finais resultantes de estratégias agressivas em termos de preço e/ou oferta), o risco de preço (alterações das matérias-primas em função do aumento dos custos de produção ou introdução no mercado de produtos mais baratos ou mais competitivos), o risco de inventário (perda de valor dos inventários, devido à obsolescência, deterioração, roubo, danificação ou destruição), o risco de crédito (possibilidade de os clientes não honrarem os compromissos assumidos), o risco de custos fixos (custos fixos excessivos e não suscetíveis de serem refletidos no preço dos bens), risco de orçamentação (não cumprimento dos orçamentos devido a fatores externos às empresas), risco de qualidade (não cumprimento dos padrões de qualidade devido a deficiências no controlo de qualidade), risco de I\&D (possibilidade de os custos com I\&D gerarem perdas de rendibilidade ao nível das vendas), risco de intangíveis (perda de valores dos ativos intangíveis, com impacto negativo ao nível das vendas), risco ambiental (problemas de natureza ambiental com impacto sobre os custos suportados e ao nível dos resultados obtidos), rico cambial (variação dos valores das divisas), e risco de garantia (possibilidade de os produtos comercializados necessitarem de ser reparados ou substituídos).

Em síntese, todos estes riscos podem produzir impactos negativos em termos de redução das vendas ou aumento de custos operacionais. Daí a importância em comparar os dados do mercado com os preços praticados em operações vinculadas ou, na ausência de informação sobre tais preços, as margens de rendibilidade das entidades que se assemelhem aos das entidades relacionadas. Esta análise é fundamental para a determinação dos preços de transferência.

\subsection{Procedimento a adotar}

Em primeiro lugar, deve ser feito uma análise da situação macroeconómica do mercado. Nesta primeira fase, devem ser analisados os fatores externas ao grupo, que podem contribuir para a existência ou o reforço de relações intra-grupo, e explicado algumas das situações internas ao próprio grupo, que possam ter uma influência no preço praticado, como sucede, por exemplo, no caso em que uma empresa funcione como central de compras e vende depois às restantes, ou no caso ainda de se ter criado uma única empresa do grupo que forneça serviços a todas as outras. 
Numa segunda fase, deve ser feito uma apresentação da entidade, prevendo um breve historial da empresa e do grupo, a sua localização, a forma jurídica, o montante do capital social, o número de sócios e as suas participações, o NIPC e a atividade desenvolvida. Por outro lado, devem ser apresentadas as demonstrações financeiras da empresa, bem como os indicadores de rentabilidade ao longo dos últimos anos. Devem ainda ser identificados os principais clientes, fornecedores, credores, entidades financeiras e outras entidades relevantes com os quais a empresa se relaciona. Por último, é apresentado o método de determinação de preços da empresa.

Numa terceira fase, deve ser feito uma análise funcional da entidade em que se descreve de forma pormenorizada as atividades da empresa para a qual se esta a fazer o dossier e no contexto do grupo, tendo por base o organigrama da empresa. Nesta parte, importa descrever as várias funções da empresa que surgem no organigrama (administrativa, produção, distribuição, etc), apresentar uma análise SWOT da empresa e descrever os riscos assumidos.

Numa penúltima fase, são identificadas as operações vinculadas e descritas todas as transações realizadas pela empresa na sua relação com as entidades relacionadas. Pretende-se aqui quantificar e descriminar todas as operações vinculadas, no que refere, nomeadamente, às compras, vendas e serviços.

$\mathrm{Na}$ última fase, realiza-se a análise económica das operações vinculadas. Para a determinação do preço de transferência, efetua-se uma seleção do método tradicional ou não tradicional, selecionam-se as empresas para comparar os preços com as empresas vinculadas e adotase o método que, face às circunstâncias específicas de cada operação, satisfaça de forma mais apropriada o princípio de plena concorrência. Esse método deverá assegurar o mais elevado grau de comparabilidade entre as operações vinculadas e operações entre entidades independentes. A escolha do método dita não só o preço de transferência ma determina igualmente a possível correção fiscal a ser efetuada na declaração de rendimentos.

\section{CONCLUSÃO}

Embora não exista uma regra geral em matéria de determinação dos PT, deve aplicar-se o método mais apropriado para a determinação dos preços das operações vinculadas comparativamente com os preços das operações não vinculadas. Entre os vários métodos, os métodos tradicionais constituem o meio mais direto de determinação das relações económicas e financeiras entre entidades relacionadas comparativamente com as relações de plena concorrência. Os métodos baseados no lucro da operação são métodos complementares ou subsidiários dos métodos tradicionais, que só operam naqueles casos em que não existem elementos suficientes para a sua efetiva aplicação.

A aplicação dos diversos métodos nem sempre é uma tarefa fácil devido à dificuldade em apurar o preço de plena concorrência e em 
recolher toda a informação relativa à diversidade de transações realizadas. A seleção do método mais apropriado deve, por conseguinte, ser feita de forma ponderada uma vez que a escolha do método dita qual o preço de transferência e determina a possível correção fiscal a ser efetuada na declaração de rendimentos.

Qualquer um dos métodos, tradicionais e não tradicionais, requer o conhecimento dos bens, direitos e serviços transacionáveis, das funções desempenhadas, do mercado, da disponibilidade de dados comerciais e financeiros sobre estes bens, direitos e serviços e outros critérios de comparabilidade.

Apesar dos diversos fatores que influenciam os PT e das dificuldades em aplicar os métodos de determinação dos PT, o regime em causa tem evoluído no sentido de reforçar os instrumentos necessários à determinação dos preços de plena concorrência, de sancionar fiscalmente as entidades que não cumprem as disposições legais e de combater a fraude e a evasão fiscais.

\section{BIBLIOGRAFIA}

A. C. AZEVEDO DE AMORIM, "Acordos prévios em matéria de PT", in D. LEITE DE CAMPOS, Estudos de Direito Fiscal, Almedina, 2007.

A. C. DOS SANTOS e C. CELORICO PALMA, «A regulação internacional da concorrência fiscal prejudicial», Ciência e Técnica Fiscal, n 395, julhosetembro 1999.

B. J. ARNOLD and M. J. MCINTYRE, "International Tax Primer", $2^{\circ}$ ed., Kluwer Law International, The Hague, 2002.

C. SILBERZTEIN, "The 2010 uptade to the OECD. Transfer Pricing Guidelines", in The 2010 OECD Updates. Model Tax Convention \& Transfer Pricing Guidelines. A Critical Review, Edited by D. WEBER and S. VAN WEEGHEL, Kluwer Law International BV, The Netherlands, 2011.

D. C. CLAU, Precios de transferencia en las operaciones de reestructuración empresarial. Modelo de análisis y validación, Manual Francis Lefebvre, Asociación Española de Asesores Fiscales, 2016.

G. MAISTO, "OECD Revision of Chapters I-III and IX of the Transfer Pricing Guidelines: Some Comments on Hierarchy of Methods and Recharacterization of Actual Transactions Undertaken", in The 2010 OECD Updates. Model Tax Convention \& Transfer Pricing Guidelines. A Critical Review, Edited by D. WEBER and S. VAN WEEGHEL, Kluwer Law International BV, The Netherlands, 2011.

G. PÉREZ RODILLA e I. H. ARREB, "Análisis de comparabilidad y la utilización de las bases de datos en la determinación de los precios de transferencia", in T. C. EZQUERRO, (director), Manual de Fiscalidad Internacional, 3. a ed., Instituto de Estudios Fiscales, Madrid, 2007.

G. TEIXEIRA, Preços de Transferência. Casos práticos, Vida Económica, 2006.

I. SANTOS FLORES, Régimen jurídico de los Acuerdos Previos de Valoración (APAS), Tesis Doctoral, Universidad Complutense de Madrid, 2018. 
J. A. PIRES, Os PT, Vida Económica, 2006.

J. CARVALHO ESTEVES e C. DITHMER, "Da relevância do método da margem líquida da operação em sede de PT", in G. TEIXEIRA (coord.), Preços de Transferência. Casos práticos, Ed. Vida Económica, 2006.

L. JONES RODRÍGUEZ, "Criterios para la determinación del valor normal de mercado de las operaciones vinculadas: el análisis de comparabilidad", en Fernández, Néstor Carmona (director y coordinador), Fiscalidad de las operaciones vinculadas, CISS, Valencia, 2009.

M. T. VEIGA DE FARIA, "Sobre os métodos de determinação de PT", in Ciência e Técnica Fiscal, Centro de Estudos Fiscais, n. ${ }^{0}$ 400, dezembro 2000.

OECD, Transfer Pricing Guidelines for Multinational Enterprises and Tax Administrations, julho 2017.

OECD (2018), Directrices de la OCDE aplicables en materia de precios de transferencia a empresas multinacionales y administraciones tributarias, OECD Publishing, Paris/Instituto de Estudios Fiscales, Madrid, https://doi.org/10.1787/9788480083980-es.

S. G. SHERWOOD, Comparable uncontrolled price method, in Robert Feinschreiber (eds), Transfer Pricing Handbook, vol. 1, 3a edição, John Wiley \& Sons, Inc, United States, 2001.

T. C. EZQUERRO, "Valor de mercado y ajuste secundario en las operaciones vinculadas", Revista de Contabilidad y Tributación, n. ${ }^{0}$ 312, CEF, 2009.

T. C. EZQUERRO, Fiscalidad de los precios de transferência (operaciones vinculadas), Ediciones CEF, 2016. 